\title{
Genetic Diversity of Mitochondrial DNA of Chinese Black-bone Chicken
}

\section{-Author(s)}

\section{Zhang $T^{\prime}$ \\ Du W' \\ Lu H' \\ Wang L'}

School of Bioscience and Engineering, Shaanxi University of technology, Hanzhong 723001, Shaanxi, China

\begin{abstract}
The black-bone chicken has special economic value in Chinese poultry breeds, which also are valued for the medicinal properties of their meat in traditional Chinese medicine. In order to protect the genetic resources of native black-bone chicken breeds, we analyzed the genetic diversity and matrilineal components of 64 mtDNA D-loop partial sequences from three native black-bone chicken breeds, together with reported 596 black-bone chicken mtDNA sequences from China, Japan, and Korea. A total of 108 haplotypes were observed from 73 variable sites. These domestic chicken mtDNA sequences could be assigned into seven clades (A-G). The results indicated that $71.97 \%$ of the black-bone haplotypes were related to the reference sequence that may originate from Eurasia, while the minor part of mtDNA sequences presumably derive from Southeast Asia, China, and Japan. Three clades were shared by Korean, Japanese, and Chinese black-bone chickens. These results provide basic data useful for making new breeding and conservation strategies for the black-bone chicken in China.
\end{abstract}

\section{INTRODUCTION}

Domestic chicken (Gallus domesticus) may overwhelmingly originate from the Red Jungle Fowl of Asia (Fumihito \& others 1994; Kanginakudru and others 2008). After a long-time of domestication, domestic chicken is one of the major sources of proteins in human's food. Beyond that, the domestic chickens have some other roles in entertainment, religion and ornamentation (Liu and others 2006). However, the black-bone chicken is different from the domestic chicken, and it is the unique special medical property, which was recorded in the Chinese traditional medicine dictionary about 700 years ago (Xie.,1995). The black-bone chicken, with distinct medical usage from domestic chicken attracts scientist's curiosities to explore their genetic evolution and origins.

Due to a vast territory, diverse environment, different selection targets and rearing conditions, and geographic proximity, a large variety of black-bone breeds have been developed in East Asia (Xie.,1995). To date, there are eight Chinese Silkie breeds registered in the Domestic Animal Diversity Information System (DAD-IS) of the Food and Agriculture Organization of the United Nations (http://www. dad.fao.org/). In Korea, Ogol chicken has been registered as a natural monument, which also has black features (Lee and others 2007). To fully utilize this valuable resource, we investigated these genetic resources with the aim to protect precious black-bone chicken breeds and develop new breeds.

Mitochondrial DNA (mtDNA) is maternally inherited, which provides abundantly genetic information for breed structure and maternal origins (Miao \& others 2013). mtDNA D-loop region with highly polymorphic information is a major genetic resource research tool to 
unveil the phylogenetic relationship, investigate the maternal origin, evaluate the population diversity, and determine the phylogeographic structure (Groeneveld \& others 2010; Wilkinson \& others 2012).

China has rich black-bone chicken genetic resources (Niu \& others 2002). In previous reports, researchers demonstrated the genetic diversity, phylogenetic relationship and origins by mitochondrial D-loop regions or microsatellite markers in some Chinese Silkie and Japanese fowls (Rowshan \& others 2011; Zhou \& others 2010). However, these studies displayed the evaluation of biodiversity only based on a few blackbone chicken breeds, without systematic analysis on genetic diversity and maternal origin of black-bone chicken in China. Therefore, more extensive samples of black-bone chicken are required to systematically describe the pattern of mtDNA variation, unveil maternal origin, phylogenetic relationship and phylogeographic structure of black-bone chicken breeds. In this study, we gained a large amount of available Chinese blackbone mtDNA sequences to assess the variations of 26 native breeds, including the Korean black-bone chicken breed, one Japanese black-bone chicken breed and 24 Chinese black-bone chicken breeds. We aim to determine the degree of shared maternal mtDNA haplotypes among different populations of black-bone chicken breeds in East Asian, reveal the phylogenetic relationship and maternal lineages of origin.

\section{MATERIAL AND METHODS}

\section{Sampling and Reported Data}

A total of 64 chicken samples were collected from three China native breeds (Nanchuan $=18$,

Table 1 - Sample information and genetic diversity of black-bone chicken

\begin{tabular}{|c|c|c|c|c|c|c|c|c|c|}
\hline Number & Breeds & Code & $\begin{array}{l}\text { Number(Sample } \\
\text { in this study) }\end{array}$ & Ps & $\mathrm{K}(\mathrm{k})$ & Location & $\begin{array}{c}\text { Haplotype } \\
\text { Diversity }(\mathrm{Hd})\end{array}$ & $\begin{array}{l}\text { Nucleotide } \\
\text { Diversity }(\pi)\end{array}$ & Reference \\
\hline 2 & ZengfuWugu & ZF & $27(27)$ & 20 & $81(1)$ & Chongqing, China & $0.928 \pm 0.012$ & $0.01543 \pm 0.00044$ & This study \\
\hline 4 & Ya'anWugu & YA & 11 & 20 & $9(2)$ & Sichuan, China & $0.964 \pm 0.051$ & $0.01418 \pm 0.00152$ & Liu et al., 2006 \\
\hline 5 & Sichuan Mountain Wugu & SCM & 13 & 19 & $8(1)$ & Sichuan, China & $0.910 \pm 0.056$ & $0.01312 \pm 0.00141$ & $\begin{array}{l}\text { Liu et al., 2006; } \\
\text { Miao et al., } 2010\end{array}$ \\
\hline 8 & WumengWugu & WM & 15 & 17 & 9(1) & Guizhou, Chin & $0.876 \pm 0.070$ & $0.01135 \pm 0.00159$ & Miao et al., 2010 \\
\hline 9 & GushiWugu & GS & 12 & 17 & 6 & Henan, Chia & $0.879 \pm 0.060$ & $0.01185 \pm 0.00183$ & Miao et al., 2010 \\
\hline 10 & Hubei Black Silkie & HBBS & 21 & 14 & 5 & Hubei, China & $0.767 \pm 0.051$ & $0.00859 \pm 0.00160$ & Liu et al., 2006 \\
\hline 11 & YunxianWugu & $Y X$ & 15 & 14 & $5(1)$ & Hubei, China & $0.705 \pm 0.112$ & $0.01050 \pm 0.00083$ & Miao et al., 2010 \\
\hline 12 & XuefengWugu & $X F$ & 38 & 23 & $13(1)$ & Hunan, China & $0.888 \pm 0.028$ & $0.01276 \pm 0.00061$ & Miao et al., 2010 \\
\hline 16 & Luke egg Wugu & LK & 9 & 14 & $5(1)$ & Guangxi, China & $0.833 \pm 0.098$ & $0.01276 \pm 0.00198$ & Miao et al., 2010 \\
\hline 17 & WangfengWugu & WF & 9 & 21 & 5 & Guangxi, China & $0.806 \pm 0.120$ & $0.01566 \pm 0.00271$ & Fu et al., 1999 \\
\hline 18 & Guangdong Silkie & GDS & 19 & 17 & $6(1)$ & Guangdong, China & $0.795 \pm 0.060$ & $0.01041 \pm 0.00200$ & Miao et al., 2010 \\
\hline 19 & YanjinWugu & YJ & 100 (19) & 41 & $29(12)$ & Yunnan, China & $0.778 \pm 0.072$ & $0.01106 \pm 0.00186$ & $\begin{array}{l}\text { This study and } \\
\text { Miao et al., } 2010\end{array}$ \\
\hline 20 & Tengchong & $\mathrm{TC}$ & 45 & 28 & $15(4)$ & Yunnan, China & $0.881 \pm 0.032$ & $0.01515 \pm 0.00074$ & Liu et al., 2004 \\
\hline 21 & WudingWugu & WD & 7 & 13 & $4(2)$ & Yunnan, China & $0.810 \pm 0.130$ & $0.00919 \pm 0.00277$ & Liu et al., 2006 \\
\hline 22 & Zhejiang Wugu & ZJ & 5 & 3 & $2(1)$ & Zhejiang, China & $0.400 \pm 0.237$ & $0.00232 \pm 0.00137$ & Liu et al., 2006 \\
\hline 23 & JiangshanWugu & JS & 39 & 30 & $21(13)$ & Zhejiang, China & $0.973 \pm 0.024$ & $0.01396 \pm 0.00129$ & Li et a1., 2013 \\
\hline \multirow[t]{2}{*}{24} & BairongSilkie & $B R$ & 26 & 17 & 5 & Fujian, China & $0.462 \pm 0.114$ & $0.00510 \pm 0.00182$ & Zhou et al., 2010 \\
\hline & Subtotal in China & & 528 & 65 & $97(46)$ & & $0.933 \pm 0.005$ & $0.01460 \pm 0.00025$ & \\
\hline 25 & Japan Silkie & JAS & 35 & 22 & $14(4)$ & Japan & $0.847 \pm 0.053$ & $0.01250 \pm 0.00100$ & Miyake, T. \\
\hline
\end{tabular}

Note: $K=$ number of haplotypes, $\mathrm{k}=$ number of unique haplotypes in breed. Ps = number of polymorphic sites, $\mathrm{h}=$ haplotype diversity, $\pi=$ nucleotide diversity. $\mathrm{A}$ total of 564 black-bone chicken sequences belonging to 22 breeds: Nanchuan Mountain Wugu (NC), Zengfu Wugu (ZF), Chengdu Black Silkie (CD), Ya'anWugu (YA), Sichuan Mountain Wugu (SCM), Dwarf Wugu (DW), Guizhou Mountain Wugu (GZM), WumengWugu (WM), GushiWugu (GS), Hubei Black Silkie (HB), YunxianWugu (YX), XuefengWugu (XF), Jiangsu Silkie (JS), Taihe Silkie (TH), Yugan Wugu (YG), Luke egg Wugu (LK), Wangfeng Wugu (WF), Wuding Wugu (WD), Yanjing Wugu (YJ), Tengchong (TC), Guangdong Silkie (GD), Zhejiang Wugu (ZJ), Jiangshan Wugu (JSH), Bairong Silkie (BR). 
Table S1 - Sample information of NCBI Accession number

\begin{tabular}{|c|c|c|}
\hline Breeds & Number & Accession No. \\
\hline Chengdu Black Silky & 15 & $\begin{array}{l}\text { AF512067 AF512068 AF512069 AF512070 AF512071 AF512072 AF512073 AF512074 AF512075 } \\
\text { AF512060 AF512062 AF512063 AF512064 AF512065 AF512066 }\end{array}$ \\
\hline Ya'an Wugu & 11 & $\begin{array}{l}\text { AF512331 AF512332 AF512335 AF512328 AF512334 AF512336 GU448500 AF512329 AF512330 } \\
\text { AF512333 AF512337 }\end{array}$ \\
\hline Sichuan Mountain Wugu & 13 & $\begin{array}{l}\text { AF512261 AF512262 AF512263 AF512264 AF512265 AF512266 AF512267 AF512268 AF512269 } \\
\text { AF512270 AF512271 AF512272 GU448501 }\end{array}$ \\
\hline Dwarf Wugu & 11 & $\begin{array}{l}\text { AF512117 AF512118 AF512119 AF512120 AF512121 AF512122 AF512123 AF512124 AF512125 } \\
\text { AF512126 AF512127 }\end{array}$ \\
\hline Guizhou Mountain Wugu & 38 & $\begin{array}{l}\text { AF512128 AF512129 AF512130 AF512131 AF512132 AF512133 AF512134 AF512135 AF512136 } \\
\text { AF512137 AF512138 GU448534 GU448529 GU448528 GU448527 GU448526 GU448525 } \\
\text { GU448524 GU448523 GU448522 GU448521 GU448520 GU448519 GU448518 GU448517 } \\
\text { GU448516 GU448515 GU448514 GU448513 GU448512 GU448511 GU448510 GU448509 } \\
\text { GU448508 GU448507 GU448506 GU448505 GU448504 }\end{array}$ \\
\hline Wumeng Wugu & 15 & $\begin{array}{l}\text { AY4660000 AY466001 AY466002 AY466003 GU447970 GU447969 GU447968 GU447967 } \\
\text { GU447966 GU447960 GU447959 GU447958 GU447957 GU447956 GU447955 GU447953 }\end{array}$ \\
\hline Gushi & 12 & $\begin{array}{l}\text { AF512150 AF512149 AF512148 AF512147 AF512146 AF512145 AF512144 AF512143 AF512142 } \\
\text { AF512141 AF512140 AF512139 }\end{array}$ \\
\hline Hubei Black Silky & 21 & $\begin{array}{l}\text { AF512189 AF512190 AF512191 AF512192 AF512193 AF512194 AF512195 AF512196 AF512197 } \\
\text { AF512198 AF512199 AF512200 AF512201 AF512202 AF512203 AF512204 AF512205 AF512206 } \\
\text { AF512207 AF512208 AF512209 }\end{array}$ \\
\hline Yunxian Wugu & 15 & $\begin{array}{l}\text { AF512314 AF512315 AF512309 AF512308 AF512312 AF512307 AF512310 AF512316 GU448491 } \\
\text { GU448492 GU448503 AF512311 AF512313 GU448493 GU448278 }\end{array}$ \\
\hline Xuefeng Wugu & 38 & $\begin{array}{l}\text { EU598217 GU448179 GU448676 EU598216 AF512300 AF512303 AF512304 AF512305 AF512306 } \\
\text { EU598214 GU448182 GU448184 GU448187 AF512299 EU598215 GU448188 EU598213 EF570458 } \\
\text { EU598210 EU598211 GU448190 AF512302 EU598212 EF570457 EU598207 GU448178 GU448180 } \\
\text { GU448181 GU448183 GU448186 GU448189 GU448191 AF512301 EU598209 EF570459 EU598206 } \\
\text { GU448185 EU598208 }\end{array}$ \\
\hline Jiangsu & 11 & $\begin{array}{l}\text { AF512221 AF512222 AF512223 AF512224 AF512225 AF512226 AF512227 AF512228 F512229 } \\
\text { AF512230 AF512231 }\end{array}$ \\
\hline Taihe Silky & 20 & $\begin{array}{l}\text { AF512273 AF512274 AF512275 AF512276 AF512277 AF512278 AF512279 AF512280 AF512281 } \\
\text { F512282 Y465988 Y465989 Y465990 Y465991 GU448540 GU448539 GU448536 GU448535 } \\
\text { GU448532 GU448531 }\end{array}$ \\
\hline Yugan Wugu & 4 & AY465992 AY465993 AY465994 AY465995 \\
\hline Luke egg Wugu & 9 & AF512245 AF512244 AF512243 AF512242 AF512241 AF512240 AF512239 AF512238 AF512237 \\
\hline Wangfeng Wugu & 9 & AF512283 AF512284 AF512285 AF512286 AF512287 AF512288 AF512289 AF512290 AF512291 \\
\hline Guangdong Silkie & 19 & \\
\hline Yanjing Wugu & 81 & $\begin{array}{l}\text { AY465998 GU448291 GU448293 GU448298 GU448302 GU448321 GU448331 GU448343 } \\
\text { GU448349 GU448289 GU448303 GU448306 GU448312 GU448327 GU448332 GU448350 } \\
\text { GU448352 GU448355 GU448296 GU448286 GU448304 GU448310 GU448328 GU448301 } \\
\text { GU448334 GU448314 GU448322 GU448307 GU448292 GU448329 AF512326 AY465999 } \\
\text { GU448288 GU448326 GU448335 GU448351 GU448297 GU448323 GU448325 GU448330 } \\
\text { GU448344 GU448348 GU448353 GU448295 GU448308 GU448309 GU448315 GU448318 } \\
\text { GU448320 AF512325 AF512327 GU448287 GU448300 GU448311 GU448313 GU448317 } \\
\text { GU448319 GU448333 GU448339 GU448356 GU448654 GU448655 GU448316 AF512324 } \\
\text { GU448324 GU448305 AY465996 GU448345 AY465997 GU448299 GU448336 GU448341 } \\
\text { GU448342 GU448346 GU448347 GU448354 GU448340 GU448338 GU448294 GU448337 } \\
\text { GU448290 }\end{array}$ \\
\hline Tengchong & 45 & \\
\hline Wuding Wugu & 7 & AF512298 AF512297 AF512296 AF512295 AF512294 AF512293 AF512292 \\
\hline Zhejiang Wugu & 5 & AF128335 AF128336 AF128337 AF128338 AF128339 \\
\hline Jiangshan black-bone chicken & 39 & $\begin{array}{l}\text { KF059613 KF059612 KF059611 KF059610 KF059609 KF059608 KF059607 KF059606 KF059605 } \\
\text { KF059604 KF059603 KF059602 KF059601 KF059600 KF059599 KF059598 KF059597 KF059596 } \\
\text { KF059595 KF059594 KF059593 KF059592 KF059591 KF059590 KF059589 KF059588 KF059587 } \\
\text { KF059586 KF059585 KF059584 KF059583 KF059582 KF059581 KF059580 KF059579 KF059578 } \\
\text { KF059577 KF059576 KF059575 }\end{array}$ \\
\hline Korean Ogol & 31 & $\begin{array}{l}\text { DQ629864 DQ629865 DQ629866 DQ629867 DQ629868 DQ629869 DQ629870 DQ629871 } \\
\text { DQ629872 DQ629873 DQ629874 DQ629875 DQ629876 DQ629877 DQ629878 DQ629879 } \\
\text { DQ629880 DQ629881 DQ629882 DQ629883 DQ629884 DQ629885 DQ629886 DQ629887 } \\
\text { DQ629888 DQ629889 DQ629890 DQ629891 DQ629892 DQ629893 DQ629894 }\end{array}$ \\
\hline Japanese silkie & 35 & $\begin{array}{l}\text { AB114071 AB114070 AB263976 AB263975 AB263974 AB263970 AB263969 AB263968 AB263967 } \\
\text { AB263966 AB263965 AB263964 AB263963 AB263962 AB263961 AB263960 AB263959 AB263958 } \\
\text { AB263957 AB263956 AB263955 AB263954 AB263953 AB263952 AB263951 AB263950 AB263949 } \\
\text { AB263948 AB263947 AB086102 AB007733 AB007735 AB007740 AB007746 AB007747 }\end{array}$ \\
\hline
\end{tabular}


Zengfu= 27, and Yanjin = 19). For the comparison of haplotypes, previous D-loop sequence data from 22 Chinese black-bone chicken breeds were included in the analysis, as well as Japanese Silkies and 31 Korean Ogol chicken were retrieved from GenBank. All together, a total of 594 black-bone chicken sequences belonging to 26 breeds: Nanchuan Mountain Wugu (NC), Zengfu Wugu (ZF), Chengdu Black Silkie (CD), Ya'anWugu (YA), Sichuan Mountain Wugu (SCM), Dwarf Wugu (DW), Guizhou Mountain Wugu (GZM), Wumeng Wugu (WM), Gushi Wugu (GS), Hubei Black Silkie (HB), Yunxian Wugu (YX), Xuefeng Wugu $(X F)$, Jiangsu Silkie (JS), Taihe Silkie (TH), Yuganwugu $(Y G)$, Luke egg Wugu (LK), Wangfeng Wugu (WF), Wuding Wugu (WD), YanjingWugu (YJ), Tengchong (TC), Guangdong Silkie (GD), Zhejiang Wugu (ZJ), Jiangshan Wugu (JSH), Bairong Silkie (BR), Japan Silkie (JAS) and Korean Ogol (KO). More details about the 594 mtDNA D-loop partial sequences from 26 black-bone chicken breeds are shown in Table 1 and Table S1.

\section{DNA extraction and PCR amplification}

Chicken blood samples were obtained from the wing veins and collected in $5 \mathrm{~mL}$ vacuum blood collection tubes, which were stored at $-20^{\circ} \mathrm{C}$ until use. DNA was isolated from blood samples using the phenol-chloroform procedure (Zhang \& others 2012). PCR was used to amplify a 518bp fragment in the $D$-loop hypervariable region in mtDNA by the following primer pair (mtF:5'-AGGACTACGGCTTGAAAAGC-3' and mtR:5'-ATGTGCCTGACCGAGGAACCAG-3') as previously described (Randi \& Lucchini 1998) (Table 2). PCR amplifications were performed in a $50 \mu \mathrm{L}$ volume containing $5 \mu \mathrm{L}$ of 10 xbuffer, $1.5 \mathrm{mM} \mathrm{MgCl}_{2}$, $0.25 \mathrm{mM}$ dNTPs, $0.2 \mathrm{mM}$ each primer, $1.5 \mathrm{U}$ Taq DNA polymerase (TaKaRaBiosystems, Dalian, China) and approximately 20ng genomic DNA. Thermal cycling was carried out on a BIO-RAD T100 Thermal cycler. The PCR was carried out using a standard program with 4 min denaturation at $95^{\circ} \mathrm{C}, 35$ cycles for 30 $\mathrm{s}$ at $94^{\circ} \mathrm{C}, 60 \mathrm{~s}$ at $55^{\circ} \mathrm{C}$, and $90 \mathrm{~s}$ at $72{ }^{\circ} \mathrm{C}$, and final extension for $10 \mathrm{~min}$ at $72{ }^{\circ} \mathrm{C}$ (Han \& others 2015). PCR products were purified on agarose gel according to the manufacturer's instructions, and DNA sequencing was performed using an $A B I 377$ automated sequencer (PE Applied Biosystems). The original PCR primers could be used as sequencing primers. All sample sequences were deposited in GenBank under accession numbers (MG554050MG554113).
Table 2 - Primers for PCR analysis of mtDNA D-loop target region

\begin{tabular}{llccc}
\hline $\begin{array}{l}\text { Primer } \\
\text { name }\end{array}$ & \multicolumn{1}{c}{$\begin{array}{c}\text { Primer sequences } \\
\left(5^{\prime}-3^{\prime}\right)\end{array}$} & $\operatorname{Tm}\left({ }^{\circ} \mathrm{C}\right)$ & $\begin{array}{c}\text { Length } \\
(\mathrm{bp})\end{array}$ & Locus \\
\hline $\mathrm{mtF}$ & AGGACTACGGCTTGAAAAC & 56.0 & 518 & D-loop \\
$\mathrm{mtR}$ & CGGTTCTACCTCGTCTCCC & 56.0 & & \\
\hline
\end{tabular}

\section{Data analysis}

Sequence alignments were performed using DNAman (version 6.0.40). Haplotype numbers (K), nucleotide variable sites (Ps), haplotype diversity $(\mathrm{Hd})$, nucleotide diversity $(\pi)$ and average number of nucleotide differences $(K)$ were determined with DnaSP 5.10.01 software (Librado \& Rozas 2009). The same sequences were considered to be one haplotype. Software Network 4.6 (www.fluxus-engineering.com) was used to construct a median-joining network to evaluate relationships among different samples. The network also included nine haplotypes as references representing the main clades ( $A$ to $I)$, which were found in populations originating from the Chinese and Eurasian region (Liu \& others 2006).

\section{RESULT}

\section{Genetic diversity of mtDNA D-loop region of black-bone chicken breeds}

Mitochondrial D-loop sequence variations were used to calculate Ps, K, $\mathrm{Hd}$ and $\pi$ among the chicken population (Table 1). A total of 73 polymorphic sites were detected, which represented $14.09 \%$ of the total D-loop sequence analyzed (518bp), which were far more than the 27 sites in the research of silky by Zhou et al. (Zhou \& others 2010). All these variations were either transitions or transversions, and no insertions or deletions were detected (Table S2). A total of 108 haplotypes were defined (Table 3). Hd and $\pi$ of populations are the main indices for evaluating mtDNA variation and genetic diversity of a breed or a population. Nucleotide diversity of all black-bone chicken was estimated at $0.01479 \pm 0.00021$ (Table 1). Nucleotide diversity of all black-bone chicken breeds ranged from $0.00232 \pm 0.00137$ in Wangfeng blackbone chicken to $0.01566 \pm 0.00271$ in Zhejiang blackbone chicken. One hundred and eight haplotypes were identified in 25 black-bone chicken populations. In our study, haplotype diversity was relatively quite high $(\mathrm{Hd}=0.936 \pm 0.005)$. Compared with different blackbone populations, Yugan black-bone chicken had the highest haplotype diversity ( $\mathrm{Hd}=1.000)$, followed by Jiangshan black-bone chicken $(0.973 \pm 0.024)$, and the 
Table S2 - Variable sites for 108 haplotypes observed in the black bone chicken populations

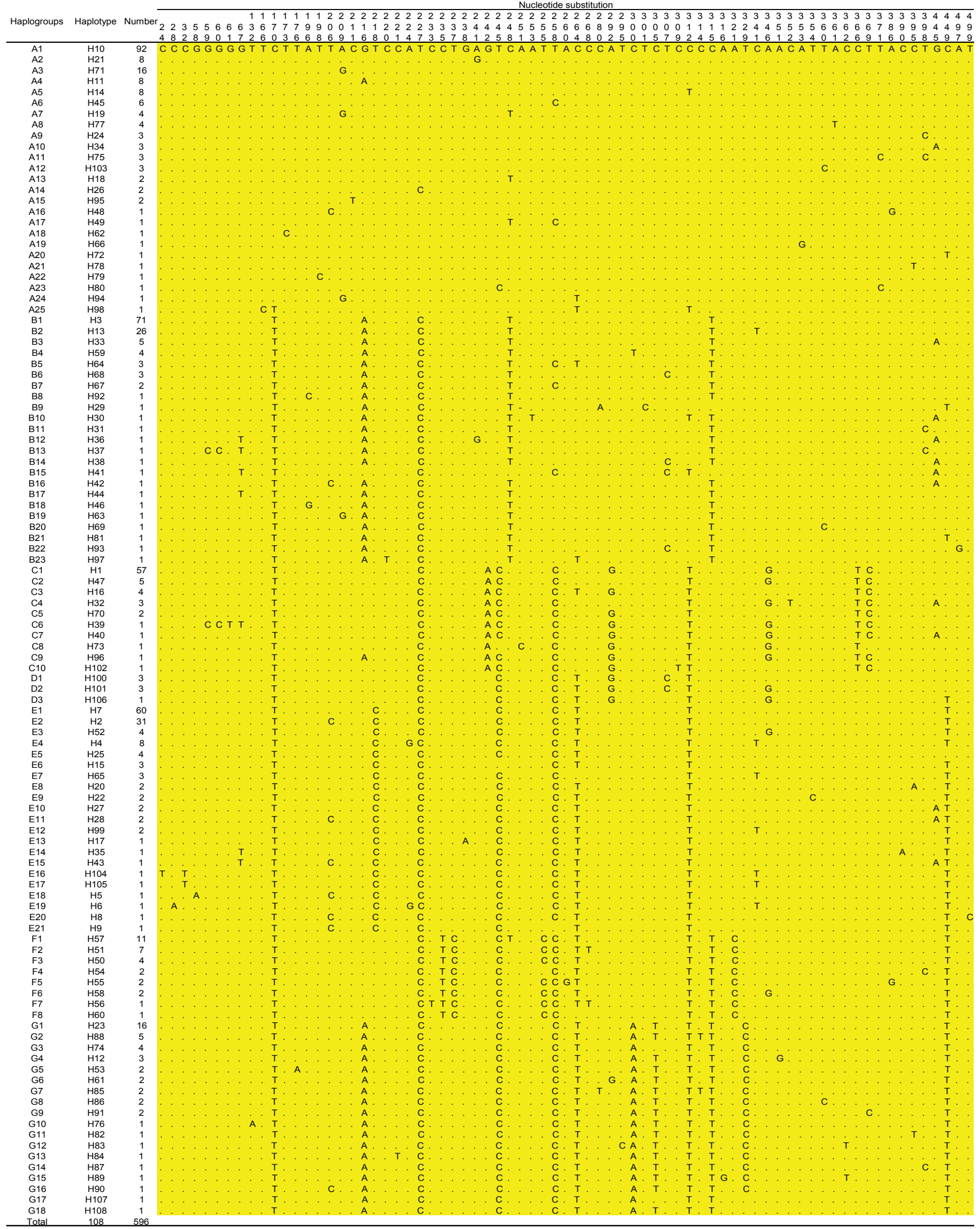



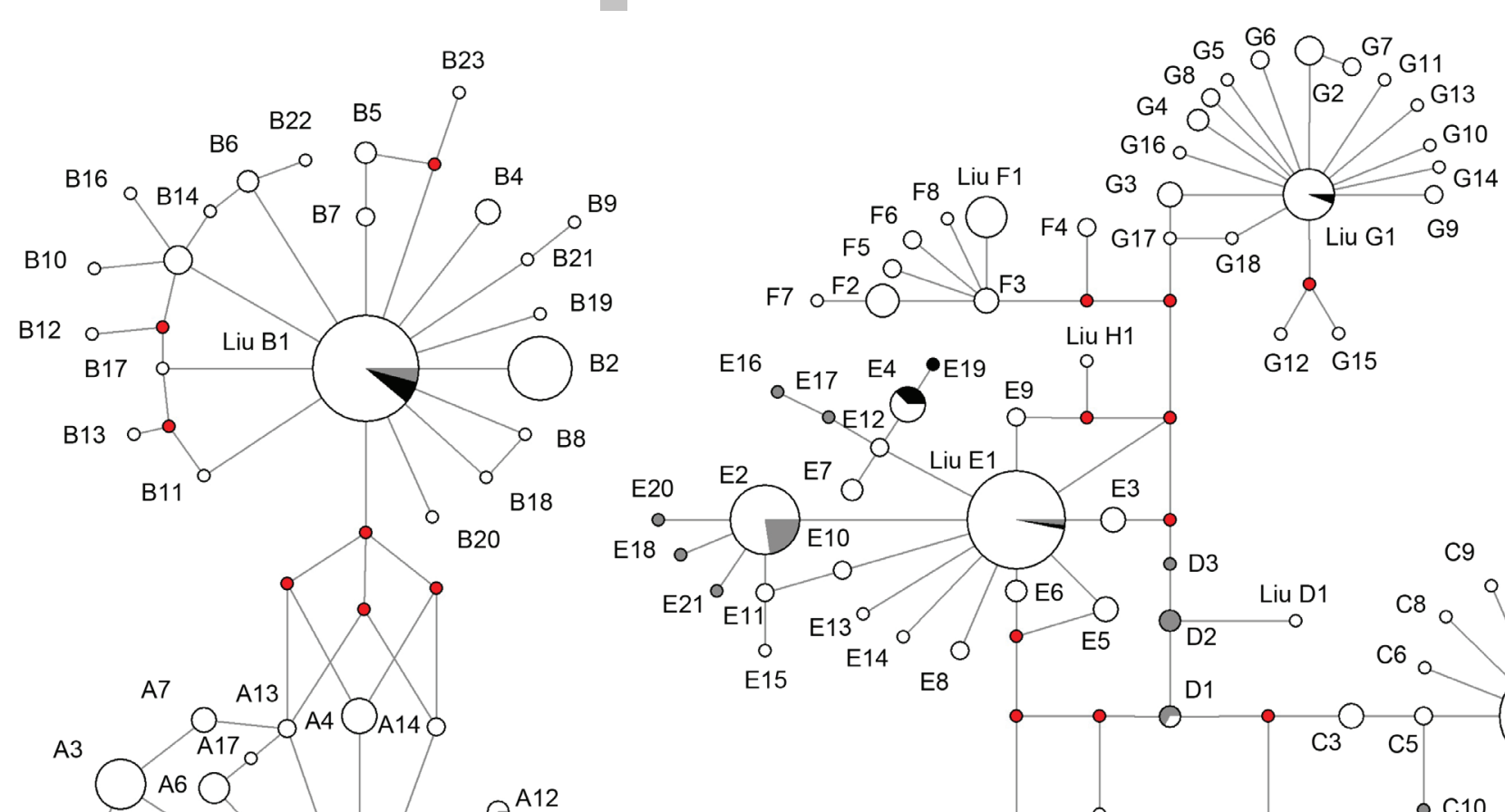

G12 G15

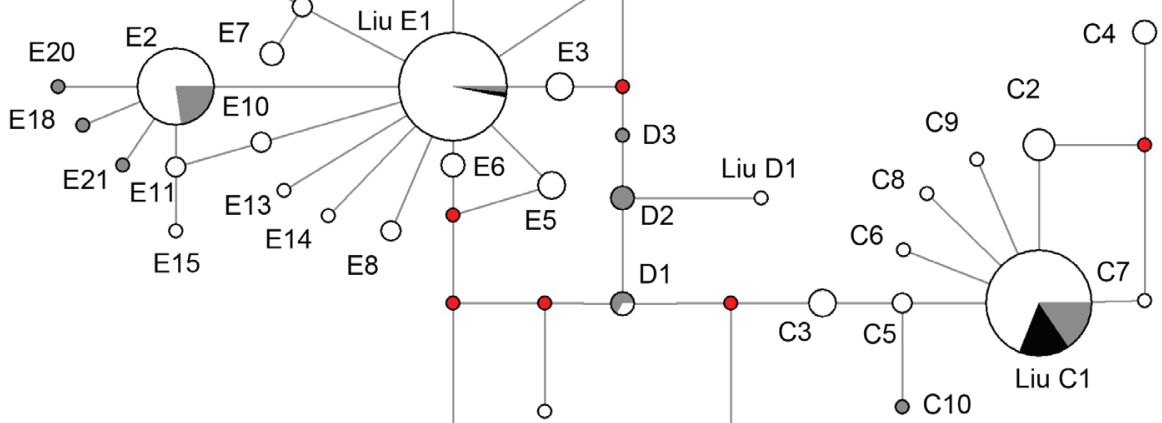

A24

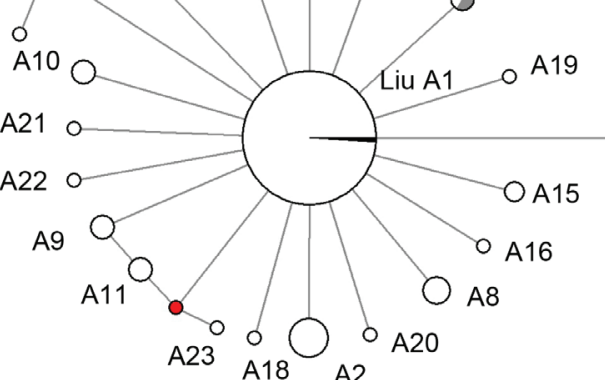

A5
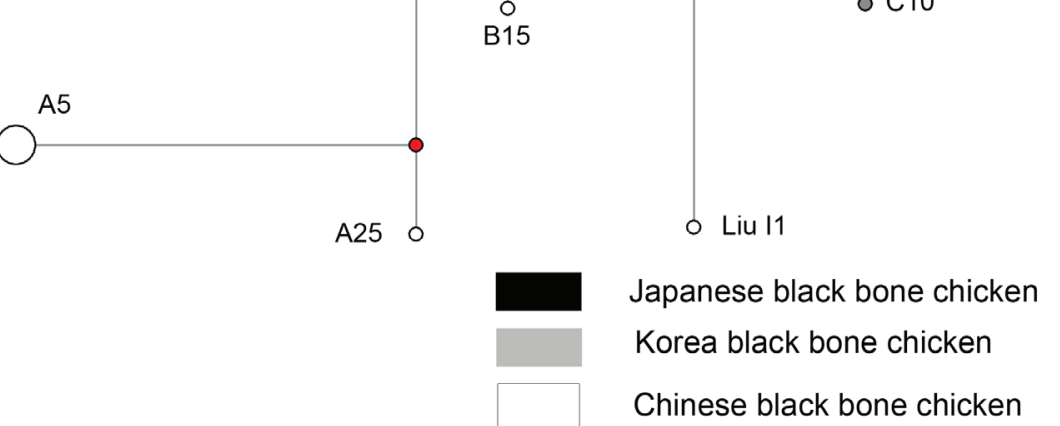

Figure 1 - The network graph of the mtDNA haplotypes in black bone chicken samples. Circle areas are proportional to haplotype frequencies. White, grey, and black colors were denoted for Chinese, Korean, and Japanese Silkies, respectively. Red points are the oretical intermediate nodes, indicates potential mutations but not found in this study. Haplotypes A1, B1, C1, D1, E1, F1 and G1 were clarified as a reference sequence.

lowest haplotype diversity was detected in Zhejiang black-bone chicken. Our research found that the haplotype diversity and nucleotide diversity of China black-bone chicken were respectively $0.933 \pm 0.005$ and $0.01460 \pm 0.00025$, and slightly exceeded that of Korean and Japanese black-bone chicken.

Additionally, these data illustrated that the genetic diversity was significantly differentamong some Chinese native black-bone chicken populations. Collectively, these results indicated that $C$ hinese black-bone chicken breeds harbored rich genetic resources, however, a few native breeds are on the verge of extinction.

\section{Phylogeny of the haplotypes and Network analysis}

The 108 haplotypes could be classified into seven divergent clades $(A-G)$ (Table 3 ). The haplotypes $A 1$, $B 1, C 1, D 1, E 1, F 1$, and $G 1$ in this study were the same as the partial sequence of each haplotype from the clades described by Liu et al. (2006), while we did not detect the $\mathrm{H} 1$ and $\mathrm{I} 1$ described by Liu et al. (Liu \& others 2006). Briefly, the clade A, B and E were the most widely distributed clades, and contained 25, 23 and 21 haplotypes, respectively. The Clades D, F, C and $G$ shared other haplotypes ranging from 3 to 18 . In each of the seven clades $(A, B, C, E, F$, and $G)$, there was a dominant haplotype, and that, haplotypes $A 1$, $B 1, C 1, E 1, E 2, F 1$, and $G 1$ were dominant and shared by $92,71,57,60,31,11$ and 16 samples, respectively. In addition, fifty-five haplotypes are unique. Meanwhile, 12 unique haplotypes $(12 / 108=11.11 \%)$ belong to Yanjing breeds, and 13 unique (13/104 = $12.03 \%)$ haplotypes belong to Jiangshan breed, and for other breeds, the number of unique haplotypes varies from one to four (Table 1). In general, all the Chinese Blackbone Chicken samples were present in clades $A, B$, $C, E, F$, and $G$, while Japanese Black-bone Chicken samples were distributed in clades $A, B, C, E$, and Korean Black-bone Chicken were only found in clades $B, C$ and $E$. The number of black-bone individuals in 
Table 3 - Haplogroup distribution frequency of black-bone chicken

\begin{tabular}{|c|c|c|c|c|c|c|c|c|}
\hline Breed & & & Hap & $\log r$ & oup & & & Total numbe \\
\hline & $A$ & $B$ & $C$ & $\mathrm{D}$ & $E$ & $\mathrm{~F}$ & G & \\
\hline Nanchuan Mountain Wugu & 12 & 1 & 1 & & 4 & & & 18 \\
\hline Zengfu Wugu & 5 & 5 & 1 & & 16 & & & 27 \\
\hline Chengdu Black Silkie & 9 & 5 & & & & & 1 & 15 \\
\hline Ya'an Wugu & 4 & 2 & 2 & & 3 & & & 11 \\
\hline Sichuan Mountain Wugu & 3 & 1 & 4 & & 5 & & & 13 \\
\hline Dwarf Wugu & 3 & 3 & & & 5 & & & 11 \\
\hline Guizhou Mountain Wugu & 26 & 1 & 3 & & 7 & & 1 & 38 \\
\hline Wumeng Wugu & 1 & 9 & & & 5 & & & 15 \\
\hline Gushi Wugu & 5 & 1 & & & 5 & & 1 & 12 \\
\hline Hubei Black Silkie & 8 & 11 & 2 & & & & & 21 \\
\hline Yunxian Wugu & 2 & 3 & 10 & & & & & 15 \\
\hline Xuefeng Wugu & 4 & 12 & 6 & & 16 & & & 38 \\
\hline Jiangsu Silkie & 4 & 3 & 4 & & & & & 11 \\
\hline Taihe Silkie & 9 & 8 & 2 & & 1 & & & 20 \\
\hline Yuganwugu & 1 & 1 & & & 2 & & & 4 \\
\hline Luke egg Wugu & 4 & 2 & 3 & & & & & 9 \\
\hline Wangfeng Wugu & 4 & 1 & 1 & & & 1 & 2 & 9 \\
\hline Guangdong Silkie & 3 & 12 & 3 & & 1 & & & 19 \\
\hline Yanjing Wugu & 39 & 5 & 5 & & 8 & 5 & 38 & 100 \\
\hline Tengchong Wugu & 14 & 3 & & & 2 & 23 & 3 & 45 \\
\hline Wuding Wugu & 2 & 4 & & & & & 1 & 7 \\
\hline Zhejiang Wugu & & 5 & & & & & & 5 \\
\hline Jiangshan Wugu & 5 & 22 & 5 & & 7 & & & 39 \\
\hline Bairong Silkie & 1 & 2 & 1 & & 22 & & & 26 \\
\hline China & 168 & 122 & 53 & & 109 & 29 & 47 & 528 \\
\hline Japanese chicken & 5 & 3 & 14 & 7 & 6 & & & 35 \\
\hline Korea chicken & & 5 & 9 & & 17 & & & 31 \\
\hline Total & 173 & 130 & 76 & 7 & 132 & 29 & 47 & 594 \\
\hline
\end{tabular}

each clade was listed in Table 2. Further more, these data elucidated obvious differences among different Chinese breeds according to the clades distribution, such as five Zhejiang Wugu samples that were only classified into B clade, and Chengdu Black Silkie, Hubei Black Silkie, Yunxian Wugu, Jiangsu Silkie, Luke egg Wugu, Wangfeng Wugu and Wuding Wugu that were not detected in the dominant clade $\mathrm{E}$. The results indicated that the genetic diversity of Chinese black-bone chicken was far abundant, and suggested different that geographic structures were detected in chicken populations. Thus, we could make a conclusion that Chinese black-bone chicken had different origins through the geographic structure of the clades.

\section{DISCUSSION}

The formation of the reconstructed network profile of Chinese black-bone chicken was in accord with previous report (Liu \& others 2006). The wide clades distribution of black-bone fowl suggests that the present black-bone chicken has high genetic divergence and has different origins of black-bone chicken. Some scholars studied the genetic relationship between Silkies and other chicken breeds using mtDNA sequence variations, and detected no obvious differentiation (Niu \& others 2002). In previous study, the distribution of main mtDNA haplogroups in chicken presented geographic pattern:clades A, B, and E were distributed ubiquitously in Eurasia; clade $C$ was prevalent in Japan and Southeast China; clades F and G were exclusive to Yunnan, China (Liu \& others 2006). In this study, the majority of Chinese chickens could be classified into clades $A, B$, and $E$. A small number of black-bone chickens were distributed in clades $F$ and $G$. The phenomenon indicates that $F$ and $G$ clades have little contribution to blackbone chicken. But a large portion of Yanjin Silky $(37.3 \%)$ was observed in clade G, and Tengchong black-bone chicken (79.31\%) was in clade $\mathrm{F}$, respectively, both of which originated from Yunnan, China. The results indicated that the two clades had great contributions to Yanjin Silky and Tengchong black-bone chicken (Liu et al., 2006). In this study, 14 haplotypes that were identified in Japanese chickens belonged to five clades $(A-E)$, and nine haplotypes identified in Korean Ogol chickens belonged to three clades ( $B, C$, and $E$ ), while clade $D$ was only found in Japanese chickens. Clade D contained gamecocks, which is a latest domestic population, and originates from Southwest China and/or surrounding areas. The results disguised itself clearly from the Chinese and Korean black-bone chickens, which were consistent with previous studies (Zhu \& others 2014). The wide distribution of black-bone chicken suggests that the present Chinese black-bone chicken has high genetic divergence, and different clades may originate from different regions.

In the present study, we investigated the D-loop SNPs and haplotypes for the identification of black-bone chicken populations in East Asia. The data indicated that the genetic resource and genetic diversity of Chinese black-bone chicken were abundant. A total of 108 haplotypes were observed from 73 variable sites, which could be assigned into seven clades. Three clades were shared by Korean, Japanese and Chinese black-bone chickens. In summary, our results provided evidences for the genetic connection across Chinese, Japanese, and Korean chicken. The wide distribution of black-bone chicken in different clades suggested that black-bone chicken was a special and unique 
domestic chicken population, and the two populations are closely related, which are multiple origins from different regions in Asia.

\section{ACKNOWLEDGEMENTS}

This research was supported by the Shaanxi province agricultural science and technology innovation and technological project (2016NY-084), National Natural Science Foundation of China (NSFC) (31402071).

\section{REFERENCE}

Fumihito A, Miyake T, Sumi S, Takada M, Ohno S, Kondo N. One subspecies of the red junglefowl (Gallus gallus gallus) suffices as the matriarchic ancestor of all domestic breeds. Proceedings of the National Academy of Sciences 1994;91:12505-12509.

Groeneveld LF, Lenstra JA, Eding $H$, Toro MA, Scherf B, Pilling D, et al. Genetic diversity in farm animals--a review. Animal Genetics 2010;41(Suppl 1):6-31.

Han H, Zhang Q, Gao K, Yue X, Zhang T, Dang R, et al. Y-single nucleotide polymorphisms diversity in chinese indigenous horse. Asian-Australasian Journal of Animal Sciences 2015;28:1066.

Kanginakudru S, Metta M, Jakati RD, Nagaraju J. Genetic evidence from Indian red jungle fowl corroborates multiple domestication of modern day chicken. BMC Evolution Biology 2008;8:174.

Lee YJ, Bhuiyan MSA, Chung HJ, Jung WY, Choi KD, Jang BG, et al. Mitochondrial DNA diversity of korean ogol chicken. Asian-Australasian Journal Animal Science 2007;20:477-481.

Librado P, Rozas J. DnaSP v5: a software for comprehensive analysis of DNA polymorphism data. Bioinformatics 2009;25:1451-1452.
Liu Y-P, Wu G-S, Yao Y-G, Miao Y-W, Luikart G, Baig M, et al. Multiple maternal origins of chickens: Out of the Asian jungles. Molecular Phylogenetics and Evolution 2006;38:12-19.

Miao YW, Peng MS, Wu GS, Ouyang YN, Yang ZY, Yu N, et al. Chicken domestication: an updated perspective based on mitochondrial genomes. Heredity 2013;110:277-82

Niu D, Fu Y, Luo J, Ruan H, Yu X-P, Chen G, et al. The origin and genetic diversity of chinese native chicken breeds. Biochemical Genetics 2002;40:163-174.

Randi E, Lucchini V. Organization and evolution of the mitochondrial dna control region in the avian genus alectoris. Journal of Molecular Evolution 1998:47:449-462.

Rowshan J, Kumagae M, Nishibori M, Yasue H, Wada Y. Japanese silkie fowls are widely distributed in the phylogenetic tree derived from mitochondrial complete d-loop nucleotide sequences. The Journal of Poultry Science 2011;48:176-180.

Wilkinson S, Wiener P, Teverson D, Haley CS, Hocking PM. Characterization of the genetic diversity, structure and admixture of British chicken breeds. Animal Genetics 2012;43:552-563.

Zhang T, Lu H, Chen C, Jiang H, Wu S. Genetic diversity of mtDNA D-loop and maternal origin of three chinese native horse breeds. AsianAustralasian Journal of Animal Sciences 2012;25:921-926.

Zhou B, Chen S-Y, Zhu Q, Yao Y-G, Liu Y-P. Matrilineal Components and genetic relationship of silkies from China and Japan. The Journal of Poultry Science 2010;47:22-27.

Zhu WQ, Li HF, Wang JY, Shu JT, Zhu CH, Song WT, et al. Molecular genetic diversity and maternal origin of Chinese black-bone chicken breeds. Genetic Molecular Research 2014;13:3275-3282. 